\title{
The Effects of a Postural Balance Training Program on Balance, Gait and Health-Related Quality of Life in Patients with Essential Tremor
}

\author{
Postüral Denge Eğitim Programının Esansiyel Tremorlu Hastalarda Denge, Yürüyüş ve \\ Sağlıkla İlgili Yaşam Kalitesine Etkisi
}

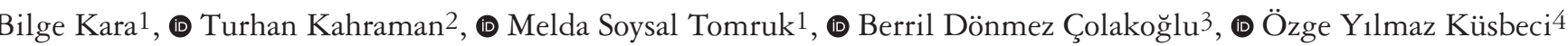 \\ 1Dokuz Eylul University School of Physical Therapy and Rehabilitation, Izmir, Turkey \\ 2Izmir Katip Celebi University Faculty of Health Sciences, Department of Physiotherapy and Rehabilitation, Izmir, Turkey \\ 3Dokuz Eylul University Faculty of Medicine, Department of Neurology, Izmir, Turkey \\ 4Health Sciences University, İzmir Bozyaka Training and Research Hospital, Clinic of Neurology, Izmir, Turkey
}

\begin{abstract}
Objective: Although the effectiveness of postural balance training on balance and gait impairment has been proven as an effective treatment approach in several patient and healthy populations, its effectiveness in patients with essential tremor (ET) is yet unknown. The aim was to examine the effects of postural balance training program on balance and gait performance, and health-related quality of life in patients with ET.

Materials and Methods: This uncontrolled clinical study included patients with ET. The outcome measures were the Postural Stability Test, Limits of Stability Test, Fall Risk Test, Activities-Specific Balance Confidence scale, Dynamic Gait Index, and Short Form-36. The assessments were performed before and after the training program. The participants underwent an 8 -week balance training designed to improve their ability to integrate multisensory inputs and postural control using a computerized balance assessment and training device.

Results: In total, 24 patients with ET participated in the study. The compliance rate was $87.5 \%$. There were significant improvements in all outcome measures of balance and gait performance, balance confidence, fall risk, and health-related quality of life (except the mental component, $p>0.05$ ) between baseline and 8 weeks $(\mathrm{p}<0.05)$.

Conclusion: Our results suggest that the balance training program is a feasible method that may have positive effects on balance performance and confidence, gait performance, and health-related quality of life in patients with ET.
\end{abstract}

Keywords: Balance training, essential tremor, gait, quality of life

$\ddot{\mathbf{O z}}$

Amaç: Postürel denge eğitiminin çeşitli hastalıklarda ve sağlıklılarda denge ve yürüme bozukluğu için etkin bir tedavi yaklaşımı olarak kanıtlanmış olmasına rağmen esansiyel tremorlu (ET) hastalarda etkinliği henüz bilinmemektedir. Bu çalışmanın amacı, postürel denge eğitim programının ET’li hastalardaki denge, yürüme performansı ve sağlıkla ilgili yaşam kalitesi üzerine etkilerini incelemek idi.

Gereç ve Yöntem: Bu kontrolsüz klinik çalışmaya ET’li hastalar dahil edildi. Sonuç ölçümleri Postürel Stabilite Testi, Stabilite Testi Sınırları, Güz Risk Testi, Aktivitelere Özgü Denge Güven Ölçeği, Dinamik Yürüme İndeksi ve Kısa Form-36'dan oluşmaktaydı. Değerlendirmeler, eğitim programından önce ve sonra gerçekleştirildi. Katılımcılar, bilgisayar tabanlı denge değerlendirme ve eğitim cihazı ile çoklu duyusal girdileri ve postürel kontrolleri bütünleştirme yeteneklerini geliştirmek için tasarlanmış 8 haftalık bir denge eğitimine tabi tutuldu.

Bulgular: Çalışmaya toplam 24 ET’li hasta katıldı. Programı tamamlama oranı \%87,5 idi. Sekiz haftanın sonunda denge ve yürüme performansı, denge güveni, düşme riski ve sağlıkla ilgili yaşam kalitesini içeren (zihinsel bileşen hariç, $\mathrm{p}>0,05)$ tüm sonuç ölçümlerinde anlamlı iyileşmeler tespit edildi $(\mathrm{p}<0,05)$.

Sonuç: Bu çalışmanın bulguları, denge eğitim programının ET’li hastalardaki denge performansı ve güvenini, yürüme performansını ve sağlıkla ilgili yaşam kalitesini olumlu etkileyebilecek uygun bir yöntem olduğunu düşündürmektedir.

Anahtar Kelimeler: Denge eğitimi, esansiyel tremor, yürüme, yaşam kalitesi

Address for Correspondence/Yazışma Adresi: Turhan Kahraman PhD, Izmir Katip Celebi University Faculty of Health Sciences,

Department of Physiotherapy and Rehabilitation, Izmir, Turkey

Phone: +90 5557219849 E-mail: turhan.kahraman@yahoo.com ORCID ID: orcid.org/0000-0002-8776-0664

Received/Geliş Tarihi: 26.05.2017 Accepted/Kabul Tarihi: 20.10.2017

Presented in: The oral abstract of this study was presented in “5. Ulusal Sağlıkta Yaşam Kalitesi Kongresi”, 11-12 Kasım 2016, Izmir, Turkey.

${ }^{\circ}$ Copyright 2018 by Turkish Neurological Society

Turkish Journal of Neurology published by Galenos Publishing House. 


\section{Introduction}

Traditionally, essential tremor (ET) is described as a neurologic disorder characterized by tremors of the head, trunk, and extremities $(1,2)$. In recent years, this traditional description of ET has changed. Novel evidence has suggested that tremor is not the sole feature of ET, it can also include cognitive and psychiatric features as well as balance and gait impairments $(3,4,5,6)$.

Several studies have indicated that patients with ET have lower balance confidence $(3,4,6,7)$. Although there is no significant difference in terms of the number of actual falls in patients with ET compared with healthy controls, the number of near misses is significantly higher among those with ET $(3,6,7)$. These findings about balance impairment suggest that patients with ET may have a higher fall risk. Although the true impact of balance and gait impairments on the quality of life and fall risk in patients with ET are not well defined, some studies have indicated that limitations in body movements may decrease quality of life in such patients $(4,8,9)$.

There are several symptomatic therapies for the treatment of ET including pharmacologic agents and surgical procedures, which are considered effective (10). However, possible therapeutic approaches to the treatment of balance and gait impairment in ET are not known. Only one study has reported improvements in gait parameters after pharmacologic treatment (11). Additionally, deep brain stimulation is a promising option to treat balance and gait impairment in patients with ET. However, the possible positive and adverse effects are required to be studied $(12,13)$.

Computerized balance systems are commonly used, which provide a valid and reliable assessment and are therapeutic devices for balance (14). They include many different programs for both the assessment and training of balance (14). The training exercises of these balance systems can improve gait, balance, and fall risk for patients with diseases such as diabetic neuropathy, cerebral palsy, and multiple sclerosis $(14,15,16)$. There is also evidence of the benefits of balance systems on balance in healthy people who had no specific disease $(17,18)$. However, to the best of our knowledge, the feasibility and effects of a postural balance training performed using a computerized balance system has not been investigated in patients with ET. The aim of this study was to examine the effects of a postural balance training on the balance and gait performance, and health-related quality of life (HRQOL) in patients with ET. The hypothesis of this study was that the postural balance training performed using a computerized balance system would be effective in improving balance and gait performance, and HRQOL in patients with ET.

\section{Materials and Methods}

\section{Study Design and Setting}

This was an uncontrolled clinical study. The participants were recruited from outpatient clinics for movement disorders in Dokuz Eylul University Hospital and Izmir Bozyaka Training and Research Hospital, Izmir, Turkey between January 2014 and January 2016. The postural balance training was conducted in the Department of Neurological Physiotherapy-Rehabilitation, School of Physical Therapy and Rehabilitation, Dokuz Eylul University, Izmir, Turkey.

\section{Participants}

Patients with ET were included in the study. The diagnosis of ET was confirmed in accordance with the Movement Disorder Society consensus statement by two neurologists experienced in movement disorders (2). According to the Movement Disorder Society consensus statement, patients were diagnosed as having ET when they had bilateral postural tremor with or without kinetic tremor, involving the hands and forearms that was visible and persistent (tremor of other body parts would be present in addition to upper limb tremor). Bilateral tremor would be asymmetric. Tremor was reported by patient to be persistent, although the amplitude would fluctuate. Tremor would or would not produce disability (2). The duration of the tremor had to be longer than 5 years (2). The exclusion criteria were having Mini-Mental State Examination scores <24 (19); the presence of other concomitant neurologic disorders; significant musculoskeletal abnormalities or pain, cardiovascular disease, or respiratory disease that would interfere with study procedures or affect safety; severe visual impairments or cooperation problems that might affect the training protocol; current or recent participation in another exercise programs.

All participants who met the inclusion criteria were recruited to the study. No specific evaluation was performed to investigate the patients' balance as to whether there was a balance impairment. All participants continued with only the study training (i.e. they did not receive routine physiotherapy during the study period).

Ethical approval was obtained from Noninvasive Research Ethics Board of Dokuz Eylul University (approval number: 2014/06-26 and date: 13.02.2014) and the written informed consent was obtained from all the participants.

\section{Assessments}

Each participant was assessed by the same examiner (BK) who is specialized in neurological physiotherapy. The examiner did not participate in the training sessions [i.e. the physiotherapists who performed the assessments (BK) and treatments (TK and MST) were different]. The demographic and clinical characteristics of the participants were recorded. The following assessment methods were performed before and after the balance training program.

The Dynamic Gait Index (DGI) is a comprehensive tool to assess gait, balance and fall risk (20); therefore, it was determined as the primary outcome measure, the remaining measures were secondary outcome measures.

\section{Balance Performance Assessments}

The Balance System ${ }^{\text {TM }}$ SD with a 12.1" display (Model: 115 VAC, Biodex Medical Systems, Inc., New York, USA) was used to assess balance performance with following the Operation/Service Manual of the Balance System ${ }^{\mathrm{TM}}$ SD (21).

\section{The Postural Stability Test}

The Postural Stability Test emphasizes an individual's ability to maintain center of balance. Before the test, the settings were prepared for the participants (21). Three trials with a 20-second duration were repeated on the stable platform while the participant was trying to stand upright with a two-leg stance. The participant's performance was noted as a stability index, which represents the variance of platform displacement in degrees from level. A high number is related with a lot of motion during the test, which is indicative of poor postural balance control (21). 


\section{The Limits of Stability (LOS) test}

The LOS test, which is a good indicator of dynamic control within a normalized sway envelope, challenges individuals to move and control their center of gravity within their base of support (21). During each test trial, individuals must shift their weight to move the cursor from the center target to a blinking target and back as quickly and with as little deviation as possible. The same process was repeated for each of nine targets in random order. Lower scores or increased times to complete the test indicate decreased LOS performance (21).

\section{Fall Risk Test}

The fall risk test identifies potential fall candidates. The test results are compared with age-dependent normative data by the software (21). Scores higher than normative values suggest that the person has a fall risk. The fall risk test was performed using the dynamic platform (between stability level 12 to 8 ) of the Balance System ${ }^{\text {TM }}$ SD with the patients' eyes open during a period of 20 seconds for three trials. The participant's performance was noted as the overall stability index.

\section{Balance Confidence}

The Activities-specific Balance Confidence (ABC) scale was used to assess the balance confidence of the participants. The $\mathrm{ABC}$ scale includes 16 items that ask patients to rate their level of confidence in performing activities without falling or experiencing a sense of unsteadiness (22). Lower scores indicate less balance confidence. The Turkish ABC Scale was found as a reliable and valid tool for measuring self-perceived balance confidence (23).

\section{Gait and Dynamic Balance Performance}

The DGI is a clinical tool to assess gait, balance, and fall risk. The DGI was used to assess the ability to modify balance while walking in the presence of external demands (20). The DGI includes eight items that evaluate maintenance of balance during gait. The items are scored 0 to 3 and higher scores indicate better gait and balance performance, and less fall risk (20).

\section{Health-related Quality of Life}

The HRQOL was assessed using the Short Form-36 (SF36), which consists of eight scales including vitality, physical functioning, bodily pain, general health perceptions, physical role functioning, emotional role functioning, social role functioning and mental health $(24,25)$. Two main scores were presented as physical health and mental health. Higher scores indicate higher HRQOL. The Turkish version of the SF-36 was found as a valid and reliable tool to assess the HRQOL (26).

\section{Postural Balance Training Program}

The participants underwent an 8-week balance training program that was designed to improve their ability to integrate multisensory inputs and challenge postural control using the Balance System ${ }^{\mathrm{TM}}$ SD. All participants performed balance training for approximately 30 minutes per session, once a week for 8 weeks using postural stability, LOS, and maze control training parameters on the Balance System ${ }^{\mathrm{TM}} \mathrm{SD}$ under the supervision of two physiotherapists (TK and MST). The Balance System ${ }^{\mathrm{TM}} \mathrm{SD}$ has static and unstable platforms that move in response to changes in the participant's center of mass; it also has 12 stability levels (21). At weeks 1 and 2 of the balance training program, participants were given a 5-minute warm up consisting of tracing predictable patterns and then static postural stability and LOS training for 25 minutes. At weeks 3 and 4, the participants performed static LOS on the Balance System ${ }^{\mathrm{TM}} \mathrm{SD}$, but the stability level of platform was progressively decreased from static to level 10 for postural stability training. At weeks 5 and 6, the stability level of the platform was decreased from level 10 to level 8 for postural stability training, and maze control training was included in the program. In the maze control training, the participants followed a reproducible pattern of movement throughout a maze in both static and dynamic environments. Three skill levels were used to create a simple or more difficult environment for the participants to navigate through. Participants who could tolerate this also performed the LOS training on the dynamic platform. At weeks 7 and 8 , the stability level of the platform was decreased from 8 to 6 for postural stability training and participants who could tolerate these changes also performed maze control training on the dynamic platform to facilitate progression.

\section{Statistical Analysis}

The characteristics of the participants were described using the descriptive statistics. Median and interquartile range (IQR) were reported for continuous variables, and the categorical variables were reported as number and percentage because of the nonnormal distribution of the data, which was explored using the Shapiro-Wilk test and histograms. The comparison before and after training was made using the Wilcoxon signed-rank test. Statistical significance was set at $\mathrm{p}<0.05$. To calculate Cohen's $\mathrm{d}$ effect sizes, mean and standard deviation were presented. The effect sizes were interpreted as small $(d=0.2)$, medium $(d=0.5)$, and large $(\mathrm{d}=0.8)$. Data were analyzed using the $\mathrm{IBM}^{\circledR}$ SPSS ${ }^{\circledR}$ (ver. 23.0; IBM Corp., Armonk, NY, USA) for Windows software.

\section{Results}

The study included 24 patients with ET (16 males) with a median age of 63.5 years (IQR: 54.0-70.75) years; however, three participants (two males) did not complete the 8-week balance training because of personal reasons (unplanned travel to another city). Therefore, the dropout rate was calculated as $12.5 \%$. No participants reported any adverse effects, and medications were not changed during the study period. The baseline demographic and clinical characteristics of the participants are presented in Table 1 .

Table 2 presents the changes in balance and gait performance, balance confidence, fall risk, and HRQOL from baseline to 8 weeks after the balance training. There were significant improvements in all outcome measures of balance and gait performance, and balance confidence from baseline to 8 weeks after the balance training $(\mathrm{p}<0.05)$. Although there was a significant improvement in SF36 physical component $(\mathrm{p}<0.05)$, the mental component did not significantly change $(\mathrm{p}>0.05)$. All of the effect sizes were medium to large (except SF-36 mental component) (Table 2). Considering the magnitude of the effect sizes, it seems that balance training has a very large impact on dynamic postural control (LOS) and fall risk. 


\section{Discussion}

To the best of our knowledge, this is the first study to examine the feasibility and effects of postural balance training in patients with ET. The results indicate that the 8 -week balance training is a feasible method that may improve balance performance, gait performance, balance confidence, and HRQOL. Additionally, the training may cause a reduction in falls.

Table 1. Baseline demographic and clinical characteristics of the participants $(n=24)$

\begin{tabular}{lcc} 
& Median & IQR \\
Age (years) & 63.5 & $54.0-70.75$ \\
Sex ${ }^{\dagger}$ & & \\
$\quad$ Female & 8 & 33.3 \\
$\quad$ Male & 16 & 66.7 \\
Height $(\mathrm{m})$ & 1.67 & $1.60-1.74$ \\
Weight $(\mathrm{kg})$ & 75.0 & $66.5-87.5$ \\
Body mass index $\left(\mathrm{kg} / \mathrm{m}^{2}\right)$ & 27.74 & $24.40-30.88$ \\
Level of education ${ }^{\dagger}$ & & \\
$\quad$ Primary or secondary school & 11 & 45.8 \\
$\quad$ High school & 4 & 16.7 \\
$\quad$ College or university & 9 & 37.5 \\
Marital status ${ }^{\dagger}$ & & \\
$\quad$ Married & 15 & 62.5 \\
$\quad$ Single & 9 & 37.5 \\
$\quad$ Disease duration (years) & 8.0 & $4.0-25.0$ \\
†Variable are presented as number and frequency, IQR: Interquartile range \\
\hline
\end{tabular}

The balance training program was performed in a progressive form because of the basic concept of progression in exercise physiology, meaning the intensity, difficulty, or complexity of exercises needs to be increased as the body adapts to exercise over time (27). Additionally, the visual feedback provided by the screen of the Balance System ${ }^{\mathrm{TM}}$ SD could enhance the motivation of the participants during the training sessions. With this feedback, the participants tried to re-adjust their wrong movements and this could further enhance motor learning and increase body adaptations (14).

While performing the LOS training, the participants tried to voluntarily move their center of mass to different blinking targets on the screen, which could improve the ability of producing effective movement of the center of mass during postural control because this task requires greater precision in force control (14). Several studies have also indicated that balance training could result in less center of mass displacement in response to perturbations $(14,28)$. In this study, the results of the LOS test indicated that participants' directional control significantly improved and the time to complete the test significantly; the time decreased after the balance training program.

Because the platform displacement in a sagittal plane is represented by the anterior/posterior stability index, a high score may indicate poor neuromuscular control of the anterior and posterior compartment muscles of the lower limbs (21). The anterior/posterior stability index of the participants significantly decreased after the training, which could be attributed to the improved neuromuscular control of these muscle groups. On the other hand, the platform displacement in the frontal plane was represented by medial/lateral stability index. Poor neuromuscular control of the inversion or eversion muscles of the lower legs can result in high scores in the medial/lateral stability index (21). Similarly, the medial/lateral stability index of the participants

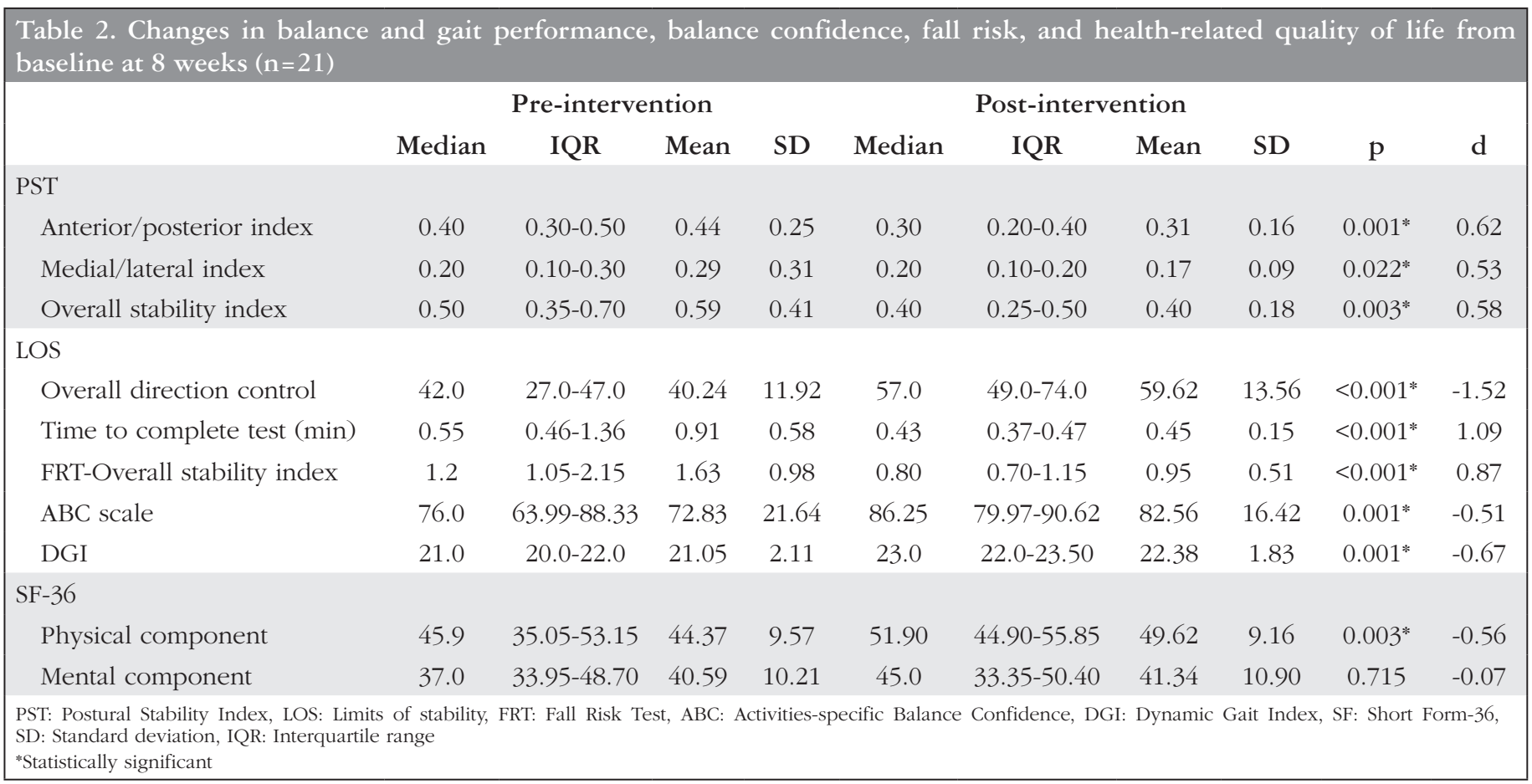


significantly decreased after the training. Additionally, the significant reduction in overall stability index of the fall risk test reflects the reduction of the potential risk for falling in patients with ET. As McAuley and Marsden (29) stated, tremor is related with motor unit firing properties, synchronized motor unit oscillations, and mechanical and feedback resonances, all of which are also related with balance control. These authors also suggested that the central nervous system structures, possibly the cerebellum, may be involved in the generation of ET (29). In the current study, balance training seemed to be effective at improving neuromuscular control, which is related with the aforementioned structures and processes. Although this study does not include neurophysiological assessments to show the real effects of the balance training on these structures and processes, we believe that it will encourage more comprehensive studies about this issue.

In the present study, all parameters assessed by the Balance System ${ }^{\mathrm{TM}}$ SD improved. However, it should be noted that the training tasks and the test protocols were similar. It has been shown that balance training induces very task-specific performance improvements (i.e. balance training can improve the performance in trained tasks but may have only minor or no effects on nontrained tasks) $(30,31,32)$. Therefore, we also used the DGI and ABC scales, which are not specific to the Balance System ${ }^{\mathrm{TM}} \mathrm{SD}$. The DGI was developed as a clinical tool to assess gait, balance, and fall risk, and it represents balance during the most common activities of daily living. Additionally, we used the ABC scale, which is a self-reported measure of balance confidence, an important outcome for clinical trials in a patient-centered approach (4). It seems that postural balance training using the Balance System ${ }^{\mathrm{TM}}$ SD may improve task-specific test results and balance in a more general manner.

Not all improvements in the performance-based measures listed above are always enough to say that balance training is effective. The ultimate goal of healthcare is to restore or preserve functioning and well-being related to health, which is defined as HRQOL (33). Thus, we measured the HRQOL of the participants to see how the balance training really affected the lives of patients with ET. The physical domain of the HRQOL as assessed by the SF-36 was significantly improved in patients with ET after the balance training. However, the mental component stayed unchanged. This is not a surprising result given that the aim of the balance training was to improve physical function not the mental component. The SF-36 includes questions about several activities of daily living such as walking and climbing stairs (24). These questions are closely related with the DGI and ABC scales. The improvement in the SF-36 - physical component was an expected result because the DGI and ABC scale scores were improved after the study. This result indicates that balance and walking ability are important life characteristics that provide a better quality of life in patients with ET. However, the HRQOL is a multi-dimensional concept that includes domains other than physical, also mental, emotional, and social functioning. In addition to rehabilitative regimes for improving physical functioning such as the current postural balance training program, other interventions for the remaining domains of $\mathrm{HRQOL}$ should also be included in the treatment of patients with ET.

There are some potential limitations to our study. First, the design of the study was inadequate to make strong judgements.
The small number of participants and lack of a control group limit the external validity of the findings. In the future, randomized controlled trials with a large sample should be conducted to show the effects of this balance training in patients with ET. Secondly, there was no follow-up period to evaluate the long-term effects of balance training. To be able to say a treatment approach is effective, it is important to know the long-term effects. Additionally, there might be a sample selection bias because all of the participants were able to walk without an assistive device. According to our experience, such programs usually address participants with higher physical function. Therefore, the current study was not able to show the feasibility and effects of the balance training program in more disabled patients with ET. Lastly, a program once per week for 8 weeks could be considered as inadequate because a limited body of data suggests that neuromotor exercise training should be performed at least twice per week (34). However, because of practical reasons, we decided to perform the program once per week and the results indicate that holding the program once weekly might be beneficial for patients with ET. Future studies should also evaluate different volumes, patterns, and progression styles because the available evidence is insufficient regarding neuromotor exercise training in patients ET and healthy and different disease populations (34).

\section{Conclusion}

In conclusion, the results of this current study suggest that 8 -week balance training is a feasible method that may be effective in improving balance performance and confidence, gait performance, and reducing fall risk in patients with ET. This balance training may also improve the physical component of the HRQOL of patients with ET. We believe that this study will help in designing randomized controlled trials, including larger sample sizes.

\section{Ethics}

Ethics Committee Approval: Ethical approval was obtained from Noninvasive Research Ethics Board of Dokuz Eylul University (approval number: 2014/06-26 and date: 13.02.2014).

Informed Consent: The written informed consent was obtained from all the participants.

Peer-review: Externally peer-reviewed.

\section{Authorship Contributions}

Concept: B.K., T.K., M.S.T., B.D.Ç., Ö.Y.K., Design: B.K., T.K., M.S.T., B.D.Ç., Ö.Y.K., Data Collection or Processing: B.K., T.K., M.S.T., Analysis or Interpretation: T.K., M.S.T., Literature Search: B.K., T.K., M.S.T., B.D.Ç., Ö.Y.K., Writing: T.K.

Conflict of interest: The authors declare that there is no conflict of interest.

Financial Disclosure: The authors completed the manuscript without the aid of any type of funding.

\section{References}

1. Pahwa R, Lyons KE. Essential tremor: differential diagnosis and current therapy. Am J Med 2003;115:134-142.

2. Deuschl G, Bain P, Brin M. Consensus statement of the Movement Disorder Society on Tremor. Ad Hoc Scientific Committee. Mov Disord 1998;13(Suppl 3):2-23 
3. Louis ED, Rao AK, Gerbin M. Functional correlates of gait and balance difficulty in essential tremor: balance confidence, near misses and falls. Gait Posture 2012;35:43-47.

4. Arkadir D, Louis ED. The balance and gait disorder of essential tremor: what does this mean for patients? Ther Adv Neurol Disord 2013;6:229-236.

5. Louis ED, Rios E, Rao AK. Tandem gait performance in essential tremor: clinical correlates and association with midline tremors. Mov Disord 2010;25:1633-1638.

6. Earhart GM, Clark BR, Tabbal SD, Perlmutter JS. Gait and balance in essential tremor: variable effects of bilateral thalamic stimulation. Mov Disord 2009;24:386-391.

7. Parisi SL, Heroux ME, Culham EG, Norman KE. Functional mobility and postural control in essential tremor. Arch Phys Med Rehabil 2006;87:13571364.

8. Chandran V, Pal PK. Quality of life and its determinants in essential tremor. Parkinsonism Relat Disord 2013;19:62-65.

9. Chunling W, Zheng X. Review on clinical update of essential tremor. Neurol Sci 2016;37:495-502.

10. Zesiewicz TA, Elble RJ, Louis ED Gronseth GS, Ondo WG, Dewey RB Jr, Okun MS, Sullivan KL, Weiner WJ. Evidence-based guideline update: treatment of essential tremor: report of the Quality Standards subcommittee of the American Academy of Neurology. Neurology 2011;77:1752-1755.

11. Klebe S, Stolze H, Grensing K, Volkmann J, Wenzelburger R, Deuschl G. Influence of alcohol on gait in patients with essential tremor. Neurology 2005;65:96-101.

12. Nazzaro JM, Lyons KE, Pahwa R. Deep brain stimulation for essential tremor. Handb Clin Neurol 2013;116:155-166.

13. Reich MM, Brumberg J, Pozzi NG, Marotta G, Roothans J, Åström M, Musacchio T, Lopiano L, Lanotte M, Lehrke R, Buck AK, Volkmann J, Isaias IU. Progressive gait ataxia following deep brain stimulation for essential tremor: adverse effect or lack of efficacy? Brain 2016;139:2948-2956.

14. El-Shamy SM, Abd El Kafy EM. Effect of balance training on postural balance control and risk of fall in children with diplegic cerebral palsy. Disabil Rehabil 2014;36:1176-1183.

15. Eftekhar-Sadat B, Azizi R, Aliasgharzadeh A, Toopchizadeh V, Ghojazadeh M. Effect of balance training with Biodex Stability System on balance in diabetic neuropathy. Ther Adv Endocrinol Metab 2015;6:233-240.

16. Eftekharsadat B, Babaei-Ghazani A, Mohammadzadeh M, Talebi M, Eslamian F, Azari E. Effect of virtual reality-based balance training in multiple sclerosis. Neurol Res 2015;37:539-544.

17. Ibrahim MS, Mattar AG, Elhafez SM. Efficacy of virtual reality-based balance training versus the Biodex balance system training on the body balance of adults. J Phys Ther Sci 2016;28:20-26.

18. Gusi N, Carmelo Adsuar J, Corzo H, Del Pozo-Cruz B, Olivares PR, Parraca JA. Balance training reduces fear of falling and improves dynamic balance and isometric strength in institutionalised older people: a randomised trial. J Physiother 2012;58:97-104.
19. Lopez MN, Charter RA, Mostafavi B, Nibut LP, Smith WE. Psychometric properties of the Folstein Mini-Mental State Examination. Assessment $2005 ; 12: 137-144$

20. Shumway-Cook A, Taylor CS, Matsuda PN, Studer MT, Whetten BK Expanding the scoring system for the Dynamic Gait Index. Phys Ther 2013;93:1493-1506.

21. Balance System SD, Operation/Service Manual. Biodex Medical Systems, Inc., New York, USA. Access Date: 15 January 2017. Available from: http:// www.biodex.com/sites/default/files/950300man_08060.pdf

22. Powell LE, Myers AM. The Activities-specific Balance Confidence (ABC) Scale. J Gerontol A Biol Sci Med Sci 1995;50:28-34.

23. Karapolat H, Eyigor S, Kirazli Y, Celebisoy N, Bilgen C, Kirazli T. Reliability, validity, and sensitivity to change of Turkish Activities-specific Balance Confidence Scale in patients with unilateral peripheral vestibular disease. Int J Rehabil Res 2010;33:12-18.

24. Demiral Y, Ergor G, Unal B, Semin S, Akvardar Y, Kivircik B, Alptekin K. Normative data and discriminative properties of short form 36 (SF-36) in Turkish urban population. BMC Public Health 2006;6:247.

25. Ware JE Jr, Sherbourne CD. The MOS 36-item short-form health survey (SF36). I. Conceptual framework and item selection. Medical Care 1992;30:473483.

26. Kocyigit $H$. Reliability and validity of the Turkish version of short form-36 (SF-36): a study in a group of patients will rheumatic diseases. Turk J Drugs Ther 1999;12:102-106.

27. Halvarsson A, Dohrn IM, Stahle A. Taking balance training for older adults one step further: the rationale for and a description of a proven balance training programme. Clin Rehabil 2015;29:417-425.

28. Rose D. Balance, posture, and locomotion. In: Spirduso WW, Francis KL, MacRae PG (eds). Physical Dimensions of Aging. 2nd ed. Champaign, IL: Human Kinetics, 2005:131-151.

29. McAuley JH, Marsden CD. Physiological and pathological tremors and rhythmic central motor control. Brain 2000;123:1545-1567.

30. Donath L, Roth R, Zahner L, Faude O. Slackline Training (Balancing Over Narrow Nylon Ribbons) and Balance Performance: A Meta-Analytical Review. Sports Med 2017;47:1075-1086.

31. Giboin LS, Gruber M, Kramer A. Task-specificity of balance training. Hum Mov Sci 2015;44:22-31.

32. Kümmel J, Kramer A, Giboin LS, Gruber M. Specificity of Balance Training in Healthy Individuals: A Systematic Review and Meta-Analysis. Sports Med 2016; $46: 1261-1271$.

33. Osoba D, King M. Meaningful differences. Assessing quality of life in clinical trials 2005;2:243-257.

34. Garber CE, Blissmer B, Deschenes MR, Franklin BA, Lamonte MJ, Lee IM, Nieman DC, Swain DP; American College of Sports Medicine. American College of Sports Medicine position stand. Quantity and quality of exercise for developing and maintaining cardiorespiratory, musculoskeletal, and neuromotor fitness in apparently healthy adults: guidance for prescribing exercise. Med Sci Sports Exerc 2011;43:1334-1359. 